\title{
Superhéroes y villanos en las clases de Educación Física
}

\section{Superheroes and villains in Physical Education classes}

\author{
* Cinthia Lopes da Silva ** Joan Ferrés i Prats
}

Lopes, C. \& Ferrés, J. (2019). Superhéroes y villanos en las clases de Educación Física. Revista Ciencias de la Actividad Física UCM, No 20(2), julio-diciembre, 1-20. DOI: http://doi.org/10.29035/rcaf.20.2.5

\section{RESUMEN}

El objeto de este trabajo es analizar una experiencia pedagógica que se incluyeron los cómics de superhéroes en las clases de Educación Física, tomando como base las contribuciones de la Comunicación Educativa. La dificultad de tratar las diferencias sociales es un problema que se agudiza en la medida en que las personas desconocen sus emociones y su singularidad, expresadas por su cuerpo. Se realizó una experiencia pedagógica con 20 alumnos de la Educación Primaria de una escuela pública del estado de São Paulo, Brasil. Se utilizaron como técnicas un diario de campo y observaciones. Se grabaron los diálogos con los alumnos. Los principales resultados fueron la construcción de conocimientos por parte de los alumnos acerca de las diferencias corporales y de valores sociales a favor del colectivo.

\section{Palabras clave}

Educación Física, comunicación, cultura, cómic. 


\section{ABSTRACT}

The objective of this work is to analyze a pedagogical experience in which superhero comics were introduced in Physical Education classes, based on the Educational Communication contributions. The difficulty of dealing with social differences is a problem that is exacerbated by the fact that people are unaware of their emotions and their uniqueness, expressed by their bodies. A pedagogical experience was carried out with 20 primary school students from a public school in São Paulo, Brazil. A field diary and observations were used as techniques. Dialogues with the students were recorded. The main results were the students' construction of knowledge about bodily differences and social values in favor of the collective.

\section{Key words}

Physical Education, communication, culture, comics.

\section{Introducción'}

Los índices más elevados de abandono de alumnos en las escuelas de Brasil se encuentran en la Educación Primaria, principalmente en los últimos años (Brasil, 2014). Diversos autores del área de Educación Física han estudiado las posibles causas de este problema, que afecta la Educación Básica en Brasil y específicamente en la disciplina de Educación Física (Darido, 2004; Fortes et al, 2012; Oliveira, 2010). Estos autores apuntan tres justificaciones para la situación antes mencionada, que son los aspectos relativos a la medición pedagógica, la repetición de contenidos y la organización curricular. Estos problemas muestran la dificultad de tratar, en el ámbito escolar, la organización del conocimiento y su proceso de medición pedagógica, de modo que el conocimiento sea más eficaz y accesible a los alumnos.

El campo de la Educación Física tiene como especificidad el conocimiento relativo al cuerpo y a las prácticas corporales, tales como el baile, la lucha, la gimnasia, los juegos y el deporte. Algunos estudios consideran estas prácticas corporales desde la idea de desarrollo motor (Binimelis, Mendez \& Vargas, 2016). Lo que pasa es que este conocimiento no recibe la debida atención para incentivar e instigar a los alumnos que logren diversas experiencias corporales, descubran las posibilidades de uso del cuerpo y reflexionen acerca de las influencias que sufren de los medios y del mercado de consumo, de las imágenes y de los mensajes, que pueden afectar el interés por las prácticas 
corporales de modo útil. Por ejemplo, perder peso, ganar masa muscular, generar cambios corporales y, por otro lado, llegar a medidas extremas, como pasar por cirugías plásticas, hacer régimen, consumir suplementos alimenticios innecesarios, comprometiendo factores biológicos, psicológicos, sociales, etcétera.

Otro elemento a considerarse es la importancia del conocimiento acerca de las prácticas corporales que tienen como función la educación para el ocio (Marcellino, 1987), pues el desarrollo de vivencias y reflexiones acerca de tales prácticas contribuye a que los alumnos sean más selectivos e independientes al elegir las actividades en el ámbito del ocio, incluso permitiéndoles acceso a referencias que faciliten su evaluación continuada de los llamamientos del mercado, de marketing y de las producciones de los medios. De este modo, los alumnos podrán desarrollar una visión crítica, sin dejarse llevar por el incentivo al consumo o por la reproducción de sentidos y valores que se divulgan diariamente y que se atribuyen al cuerpo y a las prácticas corporales.

En la búsqueda de alternativas y mejoras para la escuela y la Educación Primaria en Brasil, se identificaron autores que hacen propuestas para introducir los cómics en las disciplinas escolares como medio de potencializar y viabilizar el aprendizaje de los alumnos, puesto que sus características son favorables a la asimilación de contenidos y aprendizaje (Francisco Junior \& Uchôa, 2015; Kawamoto \& Campos, 2014; Fronza, 2016). Fronza (2016), en su investigación sobre el uso de los cómics en las clases de historia, indica algunas características de estas producciones, que contribuyen a la enseñanza y al aprendizaje, aquí sintetizadas de la siguiente forma:

- Los cómics como problematización de contenidos;

- La explotación de la representación de los personajes;

- La posibilidad de los alumnos de formular hipótesis de los contenidos trabajados;

- Los cómics para crear algo que se desea enseñar, como la evidencia histórica;

- El aspecto estético de los cómics y la construcción del conocimiento;

- El problema de las imágenes canónicas - la falta de reflexión acerca de los íconos;

- La investigación de pocas y significativas imágenes por medio de la comparación;

- El uso de cómics que causan emoción.

El autor antes mencionado indica puntos de los cómics que llevan los alumnos a la reflexión, construcción y producción de conocimiento, por su estructura "atractiva", principalmente 
por causar emoción, que es un elemento movilizador de la razón y de la construcción del conocimiento. El autor presenta un punto tal vez no tan positivo, que se refiere a las imágenes canónicas como parte de la cultura, despertando así en los alumnos los significados construidos histórica y tradicionalmente. En este caso se puede problematizar e indagar las imágenes a discutir en las clases para que los alumnos reconozcan el origen cultural e histórico de estos significados, permitiéndoles construir nuevos conocimientos.

Como los cómics son producciones de los medios y de las artes (Anselmo, 1975), estos requieren un proceso de medición del conocimiento para que los alumnos logren comprender los mensajes producidos y divulgados. La lectura de cómics es una actividad de ocio y de fácil asimilación de ideas. Esto nos hace pensar en aprovechar los cómics como un medio y objeto de educación. En este caso, tratándose de cómics específicos con superhéroes, la forma corporal de los personajes, los valores transmitidos en las historias y el mensaje (el aspecto ideológico) difundidos son elementos importantes a usarse para discutir y reflexionar con los alumnos, permitiéndoles trabajar en términos de comprensión y resignificación. Rossi Filho, Origuela \& Silva (2016), al analizar una historia del personaje SpiderGirl, ellos identificaron que los cómics de superhéroes norteamericanos son una forma de afirmación del imperialismo estadounidense, por la forma corporal de los personajes.

En los últimos cursos de la Educación Primaria y a lo largo de la Educación Secundaria, los alumnos expresan una capacidad cognitiva que les permite pensar de forma abstracta. Con esto, consideramos que una acción pedagógica a realizarse en las clases de Educación Física, viabilizaría a los jóvenes el acceso a un conocimiento vivencial, teórico-práctico, acerca de las ideologías que traen los personajes de superhéroes, y de los significados atribuidos al cuerpo y a las prácticas corporales, además de las características y valores de la sociedad contemporánea. Para esto, se hace fundamental basar las clases en un método y estrategia, para que los procesos de enseñanza y de aprendizaje sean eficaces.

Así, partimos de la premisa de que los cómics son elementos con capacidad para incentivar y viabilizar la construcción del conocimiento por parte de los alumnos de Educación Física, específicamente, por las características mencionadas, activando las emociones del lector. A este respecto, los estudios de la Comunicación Educativa (Ferrés, 2014; Ferrés \& Masanet, 2017), desde explicaciones de la neurociencia, revelan que las emociones son fundamentales para el ámbito de la Comunicación y deben ser consideradas en el proceso de la enseñanza y del aprendizaje. Los estudios 
de Fronza (2016), antes mencionado, también destacan la importancia del aspecto emocional en la experiencia que se realizó con los cómics en las clases de Historia. Aquello que se aprende corresponde inicialmente al deseo e interés por el tema, llevado por las emociones. Así, para que exista la construcción y la producción de nuevos conocimientos se necesita un esfuerzo intelectual en el que las emociones entran como ingrediente indispensable.

Ferrés (2014, p.47) habla acerca de la insuficiencia movilizadora de la razón. Según el autor, "[...] el argumento racional sin un componente emocional no conduce a una decisión eficaz". Esto se debe a que nuestro cerebro emocional tiene acceso directo al área donde se toman las decisiones Para que la razón logre influir en la decisión, hay que activarla por el componente emocional. Podemos decir que ese presupuesto de la Comunicación Educativa, con base en el conocimiento de la neurociencia, constituye una referencia útil para que se puedan rever o perfeccionar los procesos de la enseñanza y del aprendizaje en el campo de la Educación Física, considerando las emociones importantes para dicho proceso, que podrá potencializar la educación para el ocio y hacer que los contenidos de las clases sean más atractivos a los alumnos, permitiéndoles conocer mejor su cuerpo y a ellos mismos.

\section{Metodología}

La experiencia pedagógica fue desarrollada en una escuela pública en la ciudad de Piracicaba (estado de SP, Brasil). Se realizó también la revisión de literatura, que tuvo como base a Severino (2007), incluyendo la búsqueda por referencias sobre los estudios del ocio, de los cómics y de la comunicación educativa. Esa búsqueda tuvo como orientación referencias que discuten el ocio basándose en un argumento referencial cultural y obras previamente seleccionadas relativas a los cómics y a la Comunicación Educativa. Se hizo una investigación bibliográfica en la base de datos Scielo de Brasil y de España, en bibliotecas universitarias de los dos países y en la Biblioteca Digital Brasileira de Tesis y Disertaciones (BDTD). Las palabras clave en portugués y en español, sin combinaciones, fueron las siguientes: cómics, superhéroes, educación, ocio, Educación Física, Educación Primaria. En la base de datos Scielo también se utilizaron las siguientes combinaciones: cómics y superhéroes; histórias em quadrinhos (en portugués). En español, los resultados fueron solamente con la palabra Cómics. No se logró ningún resultado con el uso de las combinaciones. Para la investigación se consideró el período de enero a febrero de 2018 (en España) y de marzo a abril de 2018 (en Brasil). 
La experiencia pedagógica se realizó con 20 alumnos del último año de la Educación Primaria ( $9^{\circ}$ año)/Brasil, con edades entre 13 y 14 años, y a plicada en las clases de Educación Física. El Comité de Ética en Investigación de Brasil aprobó la investigación bajo el protocolo 75213417.2.0000.5507.

La elección por alumnos del último año de la Educación Primaria se debió al hecho de que estos alumnos son potenciales lectores de cómics y están en una fase escolar donde se pueden presentar elementos teóricos que permiten el acceso a conocimientos y hagan una lectura cualificada de las producciones del medio y de la cultura de consumo, y reflexionen sobre los temas tratados relativos al cuerpo y a los valores éticos y morales de los personajes de superhéroes.

La experiencia pedagógica se realizó en seis encuentros con los alumnos, incluyendo nueve clases efectivas en total. Cada encuentro correspondió a clases dobles. En el primer encuentro se hizo una presentación para verificar qué alumnos participarían en la investigación y en el último se utilizó sólo la primera clase para finalizar el trabajo. De esta manera, cuatro encuentros resultaron en ocho clases, y una clase extra en el último día, totalizando nueve clases.

En las clases se empleó el método de la identificación del conocimiento previo de los alumnos y la comparación con el conocimiento sistematizado. Para las estrategias de enseñan- za se utilizaron el debate/discusión y las experiencias con los cómics, cuyo enfoque es la educación para el ocio. De lo que se ha programado para las clases, nuestro foco fue demostrar cómo los alumnos fueron construyendo nuevos conocimientos con la experiencia pedagógica, que se convirtió en la construcción, vivencia y reflexión acerca de los personajes de los cómics de superhéroes y de valores sociales. Tres puntos del plan de clases fueron importantes para esto, conforme se describe más abajo:

1. Discusión/experiencia sobre la interacción con los superhéroes desde un punto de vista corporal. Desarrollo de una actividad donde los alumnos pudieron convertirse en superhéroes y demostrar sus sentimientos desde un punto de vista físico, de interacción con otros cuerpos, y cómo esta experiencia repercutió en ellos, generando indiferencia o rechazo, aceptación o rechazo de la propia corporeidad.

2. Discusión/experiencia sobre los valores éticos y morales que involucran los cómics de superhéroes, relativos a las acciones de los mismos, como, por ejemplo, salvar personas, luchar contra el mal, ser un modelo para las personas, etc.

3. Orientaciones para la creación de cómics utilizando diarios y revistas. Los alumnos crearon sus cómics de superhéroes, incluso las 
ropas hechas con papel de diarios y revistas, y elaboraron una pequeña representación teatral, donde ellos eran los personajes de los cómics de superhéroes. En este momento, nuevamente tuvieron la oportunidad de expresar sus sentimientos, demostrando conductas de rechazo o aceptación frente a los estereotipos de los superhéroes.

Vamos a describir y analizar estos tres puntos a través de tres actividades realizadas: 1) la confección de las ropas de superhéroes con papel de diarios y revistas, 2) presentación a los alumnos de forma resumida de cómics de superhéroes, destacando las características de los personajes, los valores y los aspectos en común de las historietas, y 3) la creación de una obra teatral con superhéroes. En la experiencia pedagógica, se registraron observaciones en un diario de campo y se utilizó una grabadora de voz para registrar los diálogos de los alumnos participantes. Los apuntes en el diario de campo registraron las observaciones de las manifestaciones (verbales y gestuales) de los alumnos durante las clases y los hechos ocurridos en ellas, según los contenidos propuestos.

La escuela donde se realizó la experiencia pedagógica aceptó que la investigadora (I) condujera las clases y fuera la profesora principal de dicha experiencia. La investigadora contó con la ayuda de dos profesores para realizar la experiencia pedagógica. Uno es miembro de su grupo de investigación y el segundo es profesor responsable por la disciplina de Educación Física en la escuela donde se realizó la experiencia pedagógica.

Se utilizaron como técnicas para el registro de la experiencia pedagógica un diario de campo y observaciones (para registro de las acciones y actitudes de los alumnos). Se grabaron los diálogos con los alumnos.

En la etapa de presentación y análisis se hizo la evaluación de la eficacia de la experiencia pedagógica, a partir de los presupuestos de la Comunicación Educativa de Ferrés Prats (2014). Inicialmente se hizo la interpretación de los datos, con la intención de identificar los significados de las manifestaciones de los alumnos y después comprender y analizar estos significados desde el aporte teórico de la Comunicación Educativa. Para este tipo de estudio y análisis tuvimos como base las investigaciones cualitativas, según Minayo (1994). Este tipo de investigación es innovadora en el campo de la Educación Física, por lo que no existen estudios o investigaciones con protocolos de investigación que pudieran ser la base del análisis. El esfuerzo intelectual fue establecer relaciones entre los resultados de la investigación y las predicciones teóricas de la comunicación educativa.

Los alumnos participantes en la investigación recibieron nombres abreviados para mantener en sigilo su 
identificación, respetando las exigencias y normas del Comité de Ética en Investigación de Brasil. Participaron de la investigación los alumnos: niños (Ar, Mu, Pab, Vi, An, Mar) y niñas (Ket, Jud, Y, Ma, Ca, Ce, Gi, Ta, Jue, Ka, Sa, Ve, Ra, Gio); de los cuales, en los datos presentados, los que se manifestaron verbal e individualmente (lo que permitió su identificación) fueron los siguientes: Mu, Ce, Mar, Ma, Vi. Todos los estudiantes firmaron los términos de asentimiento para participar de la investigación. Los criterios de inclusión para participar de la investigación fueron, además de firmar el término de asentimiento, estar inscrito en la escuela donde se realizó la investigación, asistir a clases de educación física regularmente y ser parte de una clase de último año de la enseñanza primaria. No tener discapacidades que comprometan la parte cognitiva. Los criterios de exclusión fueron: no asistir regularmente a las clases de educación física del último año de la enseñanza primaria y tener discapacidad cognitiva.

La experiencia pedagógica sirvió para la creación de un ambiente favorable entre los profesores y alumnos en las clases. Se propuso una dinámica de clase con diferentes estrategias, tales como las experiencias corporales en el espacio de la cancha deportiva (donde se realizaron gran parte de las clases) y las discusiones en la sala. En cada clase se presentaba inicialmente a los alumnos el tema de discusión y las actividades del día; después se realizaban las actividades según el tema y, al final de cada clase, los alumnos se reunían para concluir y explorar más sus sentimientos y comprensión.

Las actividades propuestas para las clases generaron respuestas de los alumnos. En la actividad realizada para la creación de las ropas de los superhéroes, la profesora investigadora llevó los materiales básicos, como diarios, tijeras, cintas adhesivas. Esta actividad se desarrolló por primera vez en el cuarto encuentro y, por segunda vez, en el quinto encuentro.

Inicialmente los alumnos realizaron un circuito de actividades creadas con materiales disponibles en la escuela, tales como saco de boxeo, arcos y balón medicinal, y también una cinta de Slackline que la profesora investigadora llevó a la escuela y la incluyó como una de las actividades del circuito, a la que se denominó "entrenamiento de superhéroes". Después, los alumnos se distribuyeron para realizar cada actividad, permaneciendo cierto tiempo en cada una de ellas. Las actividades específicas fueron: 1) golpear el saco de boxeo (hubo algunas orientaciones de cómo hacerlo y posicionar los brazos, para lograr más fuerza); 2) lanzar el balón medicinal en la secuencia de arcos en el suelo, tentando acertar lo más lejano posible para el balón caer dentro del arco; 3) subir en la cinta de Slackline y tentar equilibrarse (hubo algunas orien- 
taciones acerca de cómo posicionar los pies y los brazos y mantener la mirada en un punto fijo).

A continuación, en la dinámica de las clases, los alumnos se repartieron en grupos. Los alumnos que serían los superhéroes deberían manifestarse o ser elegidos por los grupos; los miembros del grupo ayudarían a crear y confeccionar las ropas de superhéroes de los cómics. Más tarde, los estudiantes realizaron una tercera actividad en que tuvieron que montar un teatro de superhéroes.

Al final de las actividades se preguntó a los alumnos cómo se sintieron durante la actividad, cuáles fueron los sentimientos despertados, observándose si había alguna manifestación de rechazo o aceptación en cuanto al modo de ser de los personajes y en relación con la trama o los elementos de los cómics de superhéroes. Se preguntó también sobre la comprensión de los otros alumnos.

\section{Resultados}

Los alumnos hicieron la actividad de entrenamiento de superhéroes y luego construyeron ropa de superhéroes con pedazos de diario y cinta adhesiva. Se crearon los siguientes superhéroes en las clases: Mujer Maravilla² (Alumna Ma), La Samuray ${ }^{3}$ (Alumna Ce) y "Súper Astro" (Alumno Vi) (personaje creado por los alumnos con habilidades de otros superhéroes). El alumno Mu tuvo la idea de crear un villano y no un héroe, llamado Thanos ${ }^{4}$. Primero el alumno dibujó el guante de Thanos (principal objeto que hace parte de la creación de este personaje villano).

Estas fueron algunas de las respuestas de los alumnos al final de la actividad:

Investigadora (I): ¿Cómo se sintieron Ustedes en el entrenamiento con los superhéroes y participando de la confección de la ropa de estos personajes?

Alumnos: Normal

l: ¿Cómo es esto?

Profesor auxiliar: ¿Qué es normal? ¿Tú tienes la costumbre de hacer ropa de superhéroes? ¿Hace tiempo que trabajas con esto? (risas).

Ce: El entrenamiento nos dejó cansados. Hicimos el lanzamiento y después, en la parte de las ropas, tuvimos la idea de hacer Samuray.

Profesor auxiliar: ¿Te sentiste bien con la ropa?

Ce: Me sentí familiarizada con la ropa.

Profesor auxiliar: Pero, ¿por qué te identificaste con este personaje?

Ce: (risas) Porque ...

Profesor auxiliar: ¿Eres descendiente de asiático? ¿Es esto? 
Ce: Sí.

I: En este grupo ¿hay alguien que ya tuvo experiencia con entrenamientos de equilibrio, caminando sobre una cinta de Slackline? ¿Quién lo hizo por primera vez? ¿Cómo se sintieron?

Alumnos: Con miedo, miedo de caer.

I: Mu y Na, ustedes están haciendo el villano Thanos. ¿Cuál fue la impresión de participar de la clase inicial y crear el disfraz de villano?

Mu: Genial

I: ¿Por qué elegiste al villano, no un superhéroe? ¿Te gusta este villano? ¿Qué es lo que él tiene en especial?

Mu: Las manoplas, las joyas para dominar el universo.

Profesor auxiliar: ¿Sigues tú este villano por los cómics?

Mu: Más por internet.

I: En la última clase, algunos alumnos comentaron acerca del entrenamiento con superhéroes, que se sintieron cansados. Vi dijo que se sintió "exhausto". ¿Qué piensan de esta comparación de Ustedes con los superhéroes? ¿Es malo sentirse cansado y no tan rápido?

Una de las alumnas: No es malo.

Uno de los alumnos: Sería bueno ser rápido.
I: ¿Sería bueno ser rápido? ¿Por qué?

Profesor auxiliar: ¿Para jugar fútbol?

Ce: De nada sirve ser asiática y no ser rápida como Samuray.

Profesor auxiliar preguntó a Ce: ¿Tú crees que tendrías más ventaja si tuviese esta habilidad?

Ce: Yo tendría agilidad, ¡sí! ¡Claro que sí!

I: Vean, ¿cómo son las características de los superhéroes que hemos tratado en clase?

Ma: ¡Bonitos!

Ustedes ya dijeron que ellos son musculosos y fuertes. Cuando los miran y se ven Ustedes (haciendo una comparación), ¿quién son Ustedes? ¿Qué perciben? ¿Qué sienten?

Ma: ¡Flacos!

Profesor auxiliar: Pero cuando usó el disfraz de Mujer Maravilla, ¿te sentiste flaca?

Ma: risas... ¡Sí! Depende...

I: Cuando dicen que el superhéroe es bonito, ¿por qué tenemos esta referencia? ¿Por qué algunos son bonitos y otros son feos? ¿De dónde viene esta referencia?

Ce: ¡Del modelo de la sociedad!

I: Esto tiene una construcción social, cuando miramos a los cómics, por ejemplo, vemos estas referencias, ¿es correcto? Entonces, 
cuando Ustedes miran y dicen que este superhéroe es musculoso y bonito, o una superheroína es bonita y tiene poderes; todo esto parece que nos llama la atención y podemos desear tener este tipo de cuerpo, ser de esta manera, ser ágil, flexible y, muchas veces, desconsideramos lo que somos, lo que nos hace particular. Lo que tenemos de más diferente unos de los otros es justamente nuestras particularidades. (...) Imaginen si todos tuviesen la misma imagen de los superhéroes, tal vez no sería entretenido. A veces, tener un detalle, un cuerpo diferente, Ilamar la atención de otra manera, también puede ser bueno. ¿Qué piensan?

Los alumnos siguieron el raciocinio, pero sin manifestaciones verbales, sólo atención.

El profesor auxiliar preguntó a uno de los alumnos: cuando usaste la ropa del superhéroe, ¿te sentiste ser capaz de hacer qué?

Uno de los alumnos: ¡Todo!

Profesor auxiliar: Explica mejor. ¿Qué es lo que solucionarías?

Ma: ¿A quién mataría primero?

Uno de los alumnos: ¡Tú! (todos sonrieron) Después, dijo: ¡es broma!

Profesor auxiliar: ¿Cuál es el súper poder de tu personaje?
Los alumnos discutieron acerca de los poderes, pero no llegaron a una conclusión por tratarse de un superhéroe creado por ellos.

Este diálogo demostró que los alumnos relataron algunos sentimientos e impresiones de los superhéroes y de los villanos. La mediación de los profesores (I y profesor auxiliar) ayudó a construir o exponer a los alumnos un punto de vista acerca de los personajes de los cómics. Esta experiencia permitió que los alumnos relatasen algunos sentimientos vividos concretamente, como el cansancio, la falta de agilidad de los superhéroes, la debilidad. Estos sentimientos, además del punto de vista del profesor, apuntan a un tipo de vivencia y mediación pedagógica, permitiendo que los alumnos se expresen, expongan sus sentimientos y sus percepciones e incluso reflexionen acerca de qué significa ser diferente a los superhéroes, o aún reconocer que no tienen la misma habilidad física de los superhéroes, sin que esto sea algo necesariamente malo. Se preparó la clase para que los alumnos tuviesen una oportunidad para reflexionar acerca de sus diferencias, en un sentido positivo, contrariamente a lo que perciben a través de los discursos e imágenes de los cómics, películas, internet y otros medios.

La segunda y la tercera actividad se realizaron en secuencia. En ese día hubo menos alumnos en clase por ser fin de año, por la etapa final de 
las clases, además de ser una semana de exámenes. Inicialmente, la investigadora presentó resumidamente los cómics de superhéroes a los alumnos, destacando la forma del cuerpo de los personajes (la historieta reunía varios superhéroes, tales como Thor, Hombre de Fierro, Supremos, Spiderman), así como la información presente en las imágenes, diálogos, además de algunos elementos comunes en historietas de mismo tipo.

I preguntó:

- ¿Qué elementos de esta pequeña parte de la historieta que leí llaman la atención respecto a lo que vieron de las imágenes y la parte de la historieta?

Alumnos: Las ropas de los personajes, las características físicas, el porte físico.

l: ¿Cuál es la apariencia de todos ellos?

Alumnos: ¡Fuertes!

I: Fuertes, musculosos. ¿Qué más? ¿Cuál es el color de la piel?

Alumnos: ¡Moreno, blancos!

I: Son blancos. La mayoría de ellos son blancos, ¿correcto? Los alumnos confirmaron la afirmación.

I: ¿Quién no es blanco?

(Algunos alumnos citaron nombres de ciertos personajes de los cómics y la profesora enfatizó que se trataba de una minoría).
Alumnos: Los villanos, en respuesta a la primera pregunta de la profesora.

I: ¿Por qué creen que el superhéroe tiene una apariencia fuerte, musculosa? ¿Por qué no podrían ser de otro modo; por ejemplo, gordo, gigante, piel de otro color?

Uno de los alumnos: ¡Por tratarse de un villano!

I: ¿Por ser villano? Pero, en esta construcción, ¿qué hay en esto?

Alumnos: Racismo, decepción.

I: Mu (se refiriendo a uno de los alumnos) Tú intentaste hacer un disfraz de villano en la última clase. ¿Por qué el villano tiene un modo corporal diferente a la de un superhéroe?

Mu: Mostrar de una forma diferente su poder, de forma sombría. Otro alumno complementó: decepción.

I: ¿Es posible que él haya tenido una historia de sufrimiento? En fin, este tipo de persona representa el lado malo y el superhéroe representa el lado bueno. ¿Concuerdan?

(Los alumnos señalaran positivamente).

I: ¿Por qué esta relación entre el superhéroe y el villano pasa en Estados Unidos? (Silencio)

I: Intentan (contestar) algo... 
Uno de los alumnos: No somos apasionados por superhéroes (cómics).

l: Pero ven películas de superhéroes... (Ellos señalaron positivamente. En la primera clase comentaron que veían películas de superhéroes).

I: Hay un punto que se denomina imperialismo cultural. Cuando Estados Unidos y Marvel construyen historietas, el objetivo es su afirmación de ellos como pueblo. ¿Por qué los superhéroes son blancos, como aparecen en la revista de historietas? Ésta es la forma de afirmación del pueblo norteamericano, como si este país fuera una referencia para el resto del mundo y, en el caso, el villano sería la parte no deseada. El término puede sonar raro, pero el imperialismo refuerza la raza, o sea, el afirmar la superioridad de una raza en relación con otra, de modo muy sutil, como transmiten las historietas.

El diálogo expresa el intento de la profesora de llevar los alumnos a pensar en el problema relativo a la forma física de los superhéroes y villanos, al imperialismo cultural estadounidense, acerca de lo que estos personajes pueden significar en el contexto de los cómics de superhéroes, con base en los estudios antes mencionados (Rossi Filho, Origuela, Silva, 2016). También una respuesta positiva de los alumnos, relativa a esto, cuando identificaron, por ejemplo, que la forma corporal de los personajes puede tener relación con el racismo, con la decepción de las personas, es decir, son indicativos de que esto derive en problemas sociales.

En la tercera actividad los alumnos elaboraron un teatro de cómics de superhéroes. Los alumnos recibieron un ejemplar de cómics de la Spider Girl, y la profesora hizo un resumen de la historieta: "Al final, la superheroína salva otro superhéroe (en este caso, el Spiderman)". Los alumnos se dividieron en dos grupos. Uno se encargó de la ropa de dos Mujeres Maravillas y el otro preparó la ropa (guante) del villano Thanos (entre ellos estaba el alumno Mu, quien tuvo la idea inicial de confeccionar la ropa de este personaje). Después de listas las ropas, se propuso a los alumnos la creación de una trama para la historieta con los personajes creados.

Ellos elaboraron una situación de persecución al villano Thanos (alumno Mar) por las Mujeres Maravillas (una de ellas, la alumna Ma, participó de la investigación, la otra no, según los criterios establecidos de la investigación que se explican en la parte del método), en el pilla pilla, o "pegapega" en portugués. Para defenderse de Thanos se lanzaría "rayo láser" (para indicar eso, el alumno movería las manos y exclamaría en voz alta "rayo láser", con poderes de paralizar a las superheroínas). Pero las dos alumnas, representando el persona- 
je, no respetaron el acuerdo de parar con el "rayo láser", resultando en frustración del alumno representando Thanos al final de la actividad. Por eso las superheroínas lograron llegar hasta él e impedir que siguiera corriendo.

Después de realizar la escena creada por los alumnos (pilla pilla), la investigadora reunió a los alumnos para evaluar la situación y hacer algunas preguntas finales, que se describen a continuación:

I: ¿Cómo evalúan la escena (en este caso, el juego que los alumnos crearon)? ¿Salió conforme se planificó?

Mar: ¡Las niñas ni esperaron que yo me teletransportara y ya vinieron por encima!

Ma: Creo que él es muy lento (risas)

I: Una cosa salió estupendo, la persecución de la heroína al villano; me parece que dio muy cierto. Es posible que se necesita un poco más de entrenamiento para la teletransportación. ¿Qué piensa, Mu? ¿Estuvo bueno? ¿Se aproximó de lo que pensaste?

(Mu balanceó la cabeza, indicando más o menos)

I: ¿Hay alguna crítica?

Los alumnos que participaron de la escena, principalmente Mar, repitieron que las niñas (Mujeres Maravillas) deberían parar en el momento en que se lanzó el rayo.
I: ¿Qué les pareció diferente por haber vivenciado una escena de los cómics? ¿Qué les pareció? ¿Qué sintieron?

Mar: Poco realista...

(Después los alumnos volvieron a comentar lo del rayo y se rieron de la situación de forma despreocupada).

Estos apuntes se refieren a las tres actividades que se realizaron con los alumnos y los cómics de superhéroes en las clases de Educación Física. A continuación analizaremos los datos presentados y utilizaremos los datos identificados en la literatura.

\section{Discusión}

Las clases que se describen y que formaron parte de la experiencia pedagógica permitieron a los alumnos construir conocimiento acerca de las diferencias corporales y de valores sociales a favor del colectivo.

La construcción de conocimiento acerca de las diferencias corporales fue posible a medida que los alumnos participaban de las actividades en las clases, que se denominaron "entrenamiento de superhéroes", y de la discusión acerca de las características de los personajes de cómics, al final de las actividades 1 y 2 . El proceso pedagógico, partiendo de estas estrategias, permitió a los alumnos identificar sus propios sentimientos y emociones y hacer una comparación con la referencia en discusión, o 
sea, los personajes de los cómics de superhéroes. Este proceso se identificó en algunos momentos del diálogo con los alumnos, como, por ejemplo, con la alumna $\mathrm{Ce}$, por tener características físicas de una persona asiática, aunque que no fuera tan ágil como la superheroína Samuray; cuando los alumnos dijeron sentir miedo de caer al caminar sobre la cinta de Slackline (sentimiento diferente al de un superhéroe que, en general, es valiente para enfrentar diferentes situaciones); o cuando identificaron los aspectos físicos (fuerza, piel de color blanco) de la mayoría de los superhéroes, al contrario de los aspectos físicos generales de los villanos.

Las situaciones que los alumnos vivencian y discuten, según los presupuestos de la Comunicación Educativa (Ferrés Prats, 2014), les permiten identificar y reconocer las propias expectativas, sus deseos, sueños e ideas que, en este caso, se refieren a los superhéroes. El ejercicio de comparación de la forma de su cuerpo y de sus capacidades físicas con aquellas de los superhéroes abarca un proceso de reconocimiento de sus limitaciones y frustraciones, y así pasan a ser conscientes de lo que son y de lo que pueden ser.

Dicho proceso pedagógico permite activar el circuito deliberativo (emocional y racional) de los alumnos, en lugar de sólo generar reacciones emocionales por el circuito automáti- co (emocional e inconsciente). Es decir, esta experiencia didáctica propició a los alumnos una experiencia para manifestar sus emociones, permitiendo una evaluación. Se trata de un elemento importante para el proceso de resignificación del conocimiento de los alumnos. Un ejemplo de cómo este ejercicio evaluativo genera nuevos significados acerca de un determinado tema es la conclusión a la que llegan algunos alumnos durante la actividad 2, cuando se asoció el personaje villano a la idea de racismo y de decepción; o, de la alumna Ce, en el diálogo de la actividad 1, que asoció las referencias de los cuerpos de los superhéroes a una producción social, cuando dijo que los adjetivos bonitos/ feos, que se atribuyó a los personajes de los cómics de superhéroes, viene de referencias y patrones sociales.

El diálogo de la actividad 2 brindó a la investigadora la oportunidad de reforzar la discusión con los alumnos acerca de las características de los personajes de los cómics de superhéroes norteamericanos, donde lograron comprender de qué se trata el imperialismo cultural, teniendo como base los estudios y los análisis anteriores de Rossi Filho, Origuela e Silva (2016). Esta discusión teórica formó parte de la experiencia pedagógica de los alumnos, que también dio muestras del aspecto concreto del proceso de inserir nuevos conocimientos a partir de una situación planificada de las clases. 
Otro aspecto que se explica en Ferrés Prats (2014) es la vivencia de la ficción y la realidad a partir de la referencia de los superhéroes. La alumna vestida de Mujer Maravilla en la actividad 1, cuando fue cuestionada por el profesor auxiliar sobre si se sintiera flaca con el disfraz, contestó: ¡sí! y, después dijo: ¡depende!, con una expresión despreocupada. Aunque es cierto que ella no lo explicó verbalmente, esto puede indicar que el hecho de haber vivido el personaje de Mujer Maravilla en su imaginación, el hecho de haberlo idealizado previamente, después se tradujo en un sentimiento de decepción, cuando percibió la realidad experimentada corporalmente. El diálogo 3 indicó lo mismo cuando el alumno Mar evaluó la escena con superhéroes, llegando a la conclusión de "poco realista". Podemos decir que la experiencia corporal no correspondió a lo esperado o imaginado.

Los alumnos Mu y Na crearon el viIlano Thanos. Demostraron comprender cómo los personajes en las producciones de superhéroes y villanos pueden influir positivamente en el aprendizaje. El personaje de villano se opone a un superhéroe. Sin embargo, los alumnos piensan en esta posibilidad, tal vez por ver que una historieta de superhéroes también necesita de villanos para tener sentido, una vez que la trama involucra la actuación de diferentes personajes. En este caso, también se aplica la afirmación de Ferrés Prats (2014) acerca de los mecanismos de implicación emo- tiva en su propuesta metodológica para el análisis de audiovisuales. Sería el caso del espectador, en nuestro contexto, los alumnos Mu y An que asumen emotivamente el punto de vista del personaje, al considerarlo un reflejo de su realidad o de sus sueños e ideales. Específicamente, en este caso, tenemos al villano.

El alumno Mu dibujó inicialmente el guante de Thanos para después confeccionarlo, realizando una acción racional al planificarlo. Los alumnos expresaron sentimientos relativos a la elección del personaje, en especial $\mathrm{Mu}$, refiriéndose al poder de tal personaje, capaz de dominar el mundo si lograse todas las joyas en el guante. El resultado de la experiencia pedagógica indicó que el alumno experimentó el sentimiento ideal que se atribuye al personaje Thanos y lo real, experimentado en el teatro con los superhéroes, que los alumnos crearon. Lo ideal sería crear el personaje orientado por la expectativa de tener el poder de dominar el universo.

Y el diálogo 3 dio muestras del peso de lo real, cuando la investigadora preguntó la opinión del alumno acerca de si la escena del teatro con superhéroes estaría de acuerdo con lo que había imaginado. El alumno Mu balanceó la cabeza, indicando que no salió exactamente como lo había imaginado. Es decir, fue una experiencia de contraste entre una situación imaginada y una situación real, en un contexto pedagógico. El ejer- 
cicio de vivenciar lo ideal y lo real es importante para la propia evaluación de los alumnos en relación con los personajes de los cómics de superhéroes.

El teatro con superhéroes se realizó a partir de un juego pilla pilla, idealizado por los alumnos con personajes de los cómics de superhéroes, donde participaron dos alumnas como Mujeres Maravillas (una fue la alumna Ma, que incluso participó en la investigación) y el villano Thanos (alumno Mar). Los alumnos combinaron las reglas antes, pero en el resultado final el alumno Mar (personaje Thanos) se mostró indignado por no respetar las reglas del juego, como debería ser. El hecho fue que las Mujeres Maravillas no hubieran respetado lo pactado, o sea, que ellas no podrían moverse cuando el personaje Thanos (alumno Mar) lanzara el rayo láser (usado para parar las superheroínas). Así el personaje Thanos (alumno Mar) podría beneficiarse en el juego, dando continuidad a más acciones y haciendo que los alumnos combinasen otras reglas para permitir que las Mujeres Maravillas lograsen vencer el rayo láser y seguir jugando. Los alumnos Mar y Mu (Mu tuvo la idea de crear el personaje Thanos) manifestaron decepción. El primer alumno, muy probablemente por haber "perdido" el juego o por no tener la oportunidad de seguir jugando; y el segundo por sentir el contraste entre lo idealizado y lo real, desde un punto de vista del significado de la acción del persona- je Thanos, que perdió el juego, como también desde un punto de vista estético idealizado.

El conjunto de datos en análisis nos permite evaluar la contribución de la experiencia pedagógica para que los alumnos identificasen problemas, como el racismo, el prejuicio, el imperialismo cultural norteamericano, a partir de la construcción de referencias corporales, además de identificar el significado del cuerpo de los personajes de cómics de superhéroes. También se observó la construcción de valores sociales a favor del colectivo con la creación del pilla pilla de superhéroes y a través de la manifestación de los alumnos que consideraron injusto que las alumnas que representaban a las Mujeres Maravillas no respetaran las reglas, lo que impidió el desarrollo y la continuidad del juego.

La construcción de la experiencia pedagógica coincide con las ideas de Marcellino (1987) al referirse a la necesidad de una educación para el ocio en el contexto de las sociedades actuales y frente a las producciones de los medios. Aunque los cómics de superhéroes formen parte de las producciones de los medios, también son producciones artísticas. La discusión acerca de los cómics o su integración en las clases de Educación Física nos muestra que permiten activar las emociones de los alumnos, haciendo que desarrollen su consciencia de los significados que traen los mensajes 
de los cómics, películas, videojuegos, personajes de superhéroes, y que sean más críticos frente a temas relativos a superhéroes, al cuerpo y a problemas sociales resultantes de las diferencias corporales entre las personas y a los valores predominantes en las sociedades capitalistas.

\section{Conclusiones}

El objetivo de este trabajo fue analizar las clases que formaron parte de una experiencia pedagógica para incluir cómics de superhéroes en el curso de Educación Física, de la Educación Primaria, desde los presupuestos de la Comunicación Educativa. Las clases permitieron a los alumnos construir conocimiento acerca de las diferencias corporales y de valores sociales a favor del colectivo. Estos conocimientos son importantes para minimizar los problemas en las clases de Educación Física, activando las emociones de los alumnos y permitiendo que logren aprender y producir nuevos conocimientos relativos al cuerpo y a las prácticas corporales. De este modo se sienten incentivados a participar efectivamente de las clases.

La experiencia pedagógica sirve como ejemplo de una forma de trabajar pedagógicamente con las emociones, de modo que los alumnos puedan conocerlas y tomen consciencia de sus ideales, deseos, expectativas, y también de los problemas que afectan a las personas y sociedades por las diferencias corporales.
Finalmente, este experimento puede servir como ejemplo a expandir en otras escuelas y como base para otras investigaciones cualitativas.

\section{Notas}

1. Este relato de experiencia forma parte de estudios de posdoctorado, financiado por la institución de vínculo de la primera autora.

2. Personaje ficticio de heroína de los cómics de la empresa estadounidense DC.

3. Personaje ficticio de una mujer oriental que fue ideada por la guionista Mylle Silva y distribuida en Brasil con el sello Tambor Cómics. El personaje se impone, lucha y desafía un sistema patriarcal para ir detrás de su familia.

4. Este personaje tiene, de especial, un guante con espacio para poner diamantes, con la finalidad de buscar todos los diamantes y, así, poder controlar el universo. En la mitología griega existe la figura de Thanatos que es la personificación de la muerte y que puede haber sido una referencia para la creación del personaje Thanos de los cómics. 


\section{REFERENCIAS BIBLIOGRÁFICAS}

Anselmo, Z. A. (1975). História em quadrinhos. Petrópolis: Vozes.

Binimelis, K., Mendez, J., Vargas, R. (2016). Estado del desarrollo motor en pre básica de una escuela municipal y un colegio particular subvencionado de la comuna de Puerto Montt. Revista Ciencias de la Actividad Física UCM, 17(1), 1-6. Recuperado de http://revistacaf.ucm.cl/ article/view/87/91

Brasil. (2014). Ministério da Educação. Recuperado de: http://www. todospelaeducacao.org.br/reportagens-tpe/32163/apenas543-dos-jovens-concluem-oensino-medio-ate-os-19-anos/

Darido, S. C. (2004). A educação física na escola e o processo de formação dos não praticantes de atividade física. Revista Brasileira de Educação Física e Esporte, 18(1), 61-80. Recuperado de http://www.revistas.usp.br/ rbefe/article/view/16551

Ferrés Prats, J. (2014). Las pantallas y el cerebro emocional. Barcelona: Gedisa.
Ferrés Prats, J., Masanet, M-J. (2017). La eficacia comunicativa en la educación: potenciando las emociones y el relato. Comunicar, 52, 51-60. Recuperado de https://www.revistacomunicar.com/index.php?contenido =detalles\&numero=52\&articu lo $=52-2017-05$

Fortes, M. de O., Azevedo, M. R.; Kremer, M. M. \& Hallal, P. C. (2012). A Educação Física escolar na cidade de Pelotas, RS: contexto das aulas e conteúdos. Journal of Physical Education. 23(1), 69-78. Recuperado de http://www.periodicos.uem.br/ojs/index.php/ RevEducFis/article/view/12617

Francisco Junior, W. E. F. \& Uchôa, A. M. (2015). Desenvolvimento e avaliação de uma história em quadrinhos: uma análise do modo de leitura dos estudantes. Educación Química, 26(2), 8793. Recuperado de https://www. sciencedirect.com/science/article/pii/S0187893X1500004X

Fronza, M. (2016). As possibilidades investigativas da aprendizagem histórica de jovens estudantes a partir das histórias em quadrinhos. Educar em Revista, 60, 4372. Recuperado de http://www. scielo.br/scielo.php?pid=S0104$40602016000200043 \&$ script $=s c$ i_abstract\&tlng=pt 
Kawamoto, E. M. \& Campos, L. M. L. (2014). Histórias em quadrinhos como recurso didático para o ensino do corpo humano em anos iniciais do Ensino Fundamental. Ciência \& Educação, 20(1), 147158. Recuperado de http://www. scielo.br/scielo.php?pid=S1516 $73132014000100009 \&$ script $=$ sci abstract\&tlng=pt

Marcellino, N. C. (1987). Lazer e educação. 11 ed. Campinas: Papirus.

Minayo, M. C. (Ed.). (1994). Pesquisa social: teoria, método e criatividade. 21ed. Rio de Janeiro: Vozes.

Oliveira, R. (2010). Na "periferia" da quadra. (Tese Doutorado). Universidad Estadual de Campinas, Campinas, Brasil.

Rossi Filho, S., Origuela, M. A. \& Silva, C. L. da. (2016). Histórias em quadrinhos de super-heróis: educação para o lazer a partir de elementos da contemporaneidade. Licere, 19(2), 260-293. Recuperado de https://periodicos.ufmg.br/index.php/licere/ article/view/1246

Severino, A. J. (2007). Metodologia do trabalho científico. São Paulo: Editora Cortez.

\section{Dirección para correspondencia}

Cinthia Lopes da Silva

Profesora de Educación Física.

Faculdade de Ciências da Saúde. Universidade Metodista de Piracicaba, San Pablo, Brasil.

Membro do Grupo de Estudo e Pesquisa Educação Física e Cultura (GEPEFIC.

https://orcid.org/0000-0002-7979-

0337

Dirección postal: Av. Júlio de Mesquita, 590, AP 92 Campinas, SP Brasil.

Contacto: cinthialsilva@uol.com.br

Recibido: 10-01-2019

Aceptado: 05-11-2019 